\title{
Endogenous endothelin maintains coronary artery tone by endothelin type A receptor stimulation in patients undergoing coronary arteriography
}

\author{
Z S Kyriakides, D T Kremastinos, E Bofilis, D Tousoulis, A Antoniadis, D J Webb
}

\begin{abstract}
Objective-To examine the contribution of endothelin type A $\left(\mathrm{ET}_{\mathrm{A}}\right)$ receptor stimulation by endogenously generated endothelin-1 (ET-1) to the maintenance of coronary vascular tone in humans.

Design-Controlled clinical study.

Setting-Tertiary cardiovascular referral centre.

Patients-14 subjects were studied, seven with normal coronary arteries and seven with coronary artery disease, mean (SEM) age, 53 (2) years.

Interventions-After diagnostic coronary arteriography, BQ-123 (a selective $\mathrm{ET}_{\mathrm{A}}$ receptor antagonist; $100 \mathrm{nmol} / \mathrm{min}$ ) in $0.9 \%$ saline, was infused into the left coronary artery at a rate of $1 \mathrm{ml} / \mathrm{min}$ for 60 minutes. Eight control subjects received saline alone.

Main outcome measures-Blood flow velocity in the left anterior descending coronary artery, measured using a Doppler flow guidewire; coronary arteriography performed at baseline and immediately at the end of the BQ-123 or saline infusion to measure the diameter of proximal and distal left anterior descending coronary artery segments.

Results-The diameter of the proximal segment increased by 6 (2)\%, while that of the distal segment increased by 12 (3)\% after BQ-123 (both p < $0.05 v$ baseline). Coronary blood flow increased from $75(10)$ to $92(10) \mathrm{ml} / \mathrm{min}$ and coronary vascular resistance decreased from 1.99 (0.36) to $1.44(0.22) \mathrm{mm} \mathrm{Hg} / \mathrm{ml} / \mathrm{min}$ after BQ-123 (both $\mathrm{p}<0.05 v$ baseline). The response to BQ-123 of patients with and without coronary artery disease was similar. There was no effect of saline in the controls.

Conclusions-Endogenously produced ET-1 contributes to the maintenance of basal coronary artery tone in humans by $\mathrm{ET}_{\mathrm{A}}$ receptor stimulation. The role of $\mathrm{ET}_{\mathrm{B}}$ receptors remains to be defined.
\end{abstract}

(Heart 2000;84:176-182)

Keywords: endothelins; arteries; blood flow; coronary circulation; angiography

The endothelins are a family of 21 amino acid peptides with potent and characteristically sustained vasoconstrictor and vasopressor actions. ${ }^{1}$ Endothelin-1 (ET-1) is the predominant isopeptide generated by the vascular endothelium. $^{2}$ ET-1 binds to at least two receptors. The $\mathrm{ET}_{\mathrm{A}}$ receptor appears to be the major one, causing vasoconstriction in arteries, while the $\mathrm{ET}_{\mathrm{B}}$ receptor mediates the release of endothelium dependent vasodilator substances and is also present in some resistance and capacitance arteries, where it can contribute to vasoconstriction. ${ }^{3}$ ET-1 may play a role in the pathophysiology of several conditions associated with vasoconstriction, including chronic heart failure, hypertension, Raynaud's disease, and renal failure. ${ }^{34} \mathrm{Re}-$ cently described inhibitors of endothelin converting enzyme and endothelin receptor antagonists may therefore have therapeutic potential as vasodilator drugs in these conditions. Endogenous production of ET-1 contributes importantly to the maintenance of basal peripheral vascular tone ${ }^{5}$ and blood pressure $^{6}$ in healthy volunteers, mainly through an effect on $\mathrm{ET}_{\mathrm{A}}$ receptors. In contrast, the main effect of endogenous ET-1 on $\mathrm{ET}_{\mathrm{B}}$ receptors in resistance arteries appears to be vasodilatation. ${ }^{78}$
ET-1 constricts human epicardial coronary arteries in vitro. ${ }^{9}$ ET- 1 and big ET- 1 administration in rat heart reduces coronary blood flow, and $\mathrm{BQ}-123$, an $\mathrm{ET}_{\mathrm{A}}$ receptor antagonist, abolishes this effect of ET- $1 .{ }^{10} \mathrm{BQ}-123$ has also been shown to reduce infarct size in a canine model of coronary occlusion and reperfusion. ${ }^{11}$ Cannan and colleagues showed that low concentrations of exogenous ET-1 in dogs, which may mimic pathophysiological concentrations, result in coronary vasoconstriction mediated predominantly by the $\mathrm{ET}_{\mathrm{A}}$ receptor, such vasoconstriction being significantly attenuated by selective $\mathrm{ET}_{\mathrm{A}}$ receptor antagonism. ${ }^{12}$ Pernow and colleagues showed in humans that exogenous ET-1 provokes a decrease in coronary sinus blood flow and an increase in coronary vascular resistance after intravenous administration. ${ }^{13}$ However, the contribution of endogenously generated ET-1 to the epicardial coronary vessel tone and artery resistance in humans is not currently known.

In the present study, therefore, we examined the contribution of $\mathrm{ET}_{\mathrm{A}}$ receptor stimulation by endogenously generated ET-1 to the maintenance of basal coronary vascular tone and blood flow in patients undergoing coronary arteriography. Plasma big ET-1 was also 
Table 1 Clinical characteristics of patients studied

\begin{tabular}{lll}
\hline & Control group $(n=8)$ & Study group $(n=14)$ \\
\hline Age (years) & $59(4)$ & $53(2)$ \\
Male/female & $6 / 2$ & $9 / 5$ \\
Baseline heart rate (beats/min) & $70(4)$ & $78(2)$ \\
Baseline mean blood pressure $(\mathrm{mm} \mathrm{Hg})$ & $110(4)$ & $110(3)$ \\
Grossly normal coronary arteries & 4 & 7 \\
Coronary artery disease & 3 & 5 \\
$\quad$ Right coronary artery & 1 & 2 \\
$\quad$ Left circumflex artery & 1 & 1 \\
Diabetes mellitus & $6.58(0.73)$ & $5.80(0.28)$ \\
Cholesterol blood concentration $(\mathrm{mmol} / \mathrm{l})$ & 1 & 4 \\
Smoking history & 3 & 4
\end{tabular}

Values are $\mathrm{n}$ or mean (SEM). No significant difference was found between the two groups.

$\star$ On antidiabetic diet only.

CHD, coronary heart disease.

measured in order to determine whether this might predict the response to BQ-123.

\section{Methods}

We studied 22 individuals, mean (SEM) age 55 (1) years, undergoing routine diagnostic cardiac catheterisation for suspected coronary artery disease (table 1). Eight made up the control group and 14 the study group. Seven of these (mean age 57 (5) years) had coronary artery disease (luminal artery stenoses $>70 \%$ in the right coronary or the left circumflex artery; the left anterior descending coronary artery was atherosclerotic but without severe lesions). Seven individuals (mean age 49 (3) years) had normal coronary arteries without any angiographic sign of atherosclerosis (although apparently normal subjects presenting to the cardiac catheterisation laboratory may often have subclinical pathology). None of the study participants had a history of hypertension or familial hyperlipidaemia.

All the coronary artery disease patients were in class 1-2 according to the Canadian Cardiovascular Society (CCS) classification. All the women were postmenopausal except for two in the study group, one with normal coronary arteries and one with coronary artery disease.

The primary objective of the study was to examine the intracoronary effects of BQ-123 in patients undergoing coronary arteriography, and a secondary objective was to examine differences between those with and without coronary artery disease.

Approval by the ethics committee was obtained and the patients gave written informed consent. The investigation conformed with the principles outlined in the Declaration of Helsinki.

\section{EXCLUSION CRITERIA}

Patients with unstable angina, left main stem disease, cardiomyopathy, decreased left ventricular systolic function or segmental wall motion abnormalities, valvular heart disease, pulmonary emphysema, claudication, systolic blood pressure $<100 \mathrm{~mm} \mathrm{Hg}$, or any concurrent acute illness were excluded from the study.

DRUGS

All drugs except aspirin were discontinued seven days before the study. Intra-arterial heparin (5000 IU) was given immediately after coronary arteriography. No other drugs apart from $\mathrm{ET}_{\mathrm{A}}$ receptor antagonists were given during the study.

STUDY PROTOCOL

All patients underwent routine diagnostic cardiac catheterisation at the time of the study, by the Seldinger technique. They were fasted and no premedication was used. After the procedure, a 7 French diagnostic coronary catheter was inserted into the ostium of the left coronary artery through an 8 French femoral sheath. A Doppler flow guidewire was inserted in the left anterior descending artery, beyond its origin and not near the origin of a side branch. The Doppler signal had to be stable before the study could proceed.

To avoid any transient haemodynamic influence of the contrast agent, ${ }^{14}{ }^{15}$ the study protocol was started 10 minutes after the end of coronary arteriography. Non-ionic contrast agents were used.

BQ-123 (cyclo \{-D-Asp-L-Pro-D=Val-LLeu-D-Trp- $\}$; American Peptide Company, Sunnyvale, California, USA) was prepared in aliquots (in $0.9 \%$ saline) after sterilised micropore filtration $(0.22 \mu \mathrm{m})$ for the removal of any bacterial or viral particles and then maintained at $-80^{\circ} \mathrm{C}$ for later use. A subset of aliquots tested negative for pyrogens before clinical use.

\section{STUDY GROUP}

Intracoronary BQ-123 (100 nmol/min) was infused at a constant rate of $1 \mathrm{ml} / \mathrm{min}$ for 60 minutes, using an infusion pump. This dose was the same as that previously given in the forearm. ${ }^{5}$ Although the blood flow in the left coronary artery is a little greater than in the forearm, the dose of BQ-123 used in the forearm was 10 times higher than the minimum required for maximal effects. ${ }^{16}{ }^{17}$ The coronary concentrations of BQ-123 were estimated to be $\sim 1 \mathrm{nmol} / \mathrm{ml}$, within the range of those having a selective action on the $\mathrm{ET}_{\mathrm{A}}$ receptor both in vitro $^{18}$ and in the human forearm circulation. ${ }^{7}$ Thus we anticipated effective blockade of the $\mathrm{ET}_{\mathrm{A}}$ receptor with this dose. The duration of the BQ-123 administration was chosen because in the forearm studies ${ }^{5}$ the maximum effect of the drug occurred after one hour of continuous infusion. The half life of BQ-123, which is a peptide, is probably brief in plasma, of the order of minutes (or at most hours). However, there is probably tight binding of $\mathrm{BQ}-123$ to the $\mathrm{ET}_{\mathrm{A}}$ receptor, and this antagonist-receptor complex may undergo internalisation within the vascular smooth muscle cell. Hence any measure of plasma half life probably underestimates the duration of the effect. ${ }^{6}$ More important from the point of view of these studies is the speed of onset of the biological effect of BQ-123 on smooth muscle tone. This is slow and in the forearm circulation takes up to 60 minutes to reach a steady state. ${ }^{57}$ In practice the current experiments were limited by the time over which measurements could be made. For this reason, and because the effects of BQ-123 are also slow to reverse, ${ }^{5}$ it would not be possible to do a study of this sort with a crossover design. 


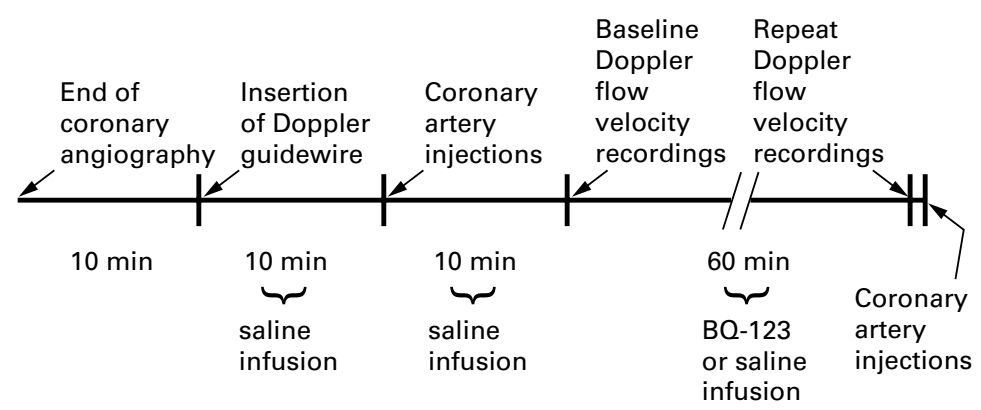

Figure 1 A flow chart with the time course of the measurements. Ten minutes after the end of coronary angiography the Doppler flow guidewire was inserted into the left anterior descending coronary artery. After 10 minutes of saline infusion, coronary artery injections were performed and after another 10 minutes of saline infusion the baseline Doppler flow velocity measurements were recorded. BQ-123 or saline infusion was then begun and continued for 60 minutes while flow velocity was stored on a videotape. Before the end of the infusion, flow velocity measurements were recorded and coronary artery injection was performed immediately afterwards.

Arterial blood pressure was monitored from the femoral sheath. Baseline haemodynamic measurements (heart rate and blood pressure) and coronary arteriography by hand injection were performed before the initiation of BQ-123 infusion and after 10 minutes of normal saline infusion $(1 \mathrm{ml} / \mathrm{min})$ while the flow guidewire was in place but disconnected from the flow map (fig 1). The Doppler flow guidewire was then connected to the flow map and, after 10 minutes of normal saline infusion, the baseline recordings of the blood flow velocity were obtained (fig 1 ). The coronary blood flow velocity trend was recorded on videotape (fig 2).

New recordings of the coronary blood flow velocity were obtained at the end of BQ-123 infusion. Because the injection of contrast material into the coronary circulation results in a typical biphasic response of coronary blood flow velocity, with an initial decrease followed by an increase in velocity caused by the hyperaemic effects of the contrast material, the velocity measured immediately before the contrast injection was used for estimation of coronary blood flow (fig 1). Coronary arteriographic injection was performed at baseline and immediately at the end of the infusion, after the velocity recordings.

CONTROL GROUP

Normal saline infusion instead of BQ-123 was given. The remainder of the procedure was the same as in the study group (fig 1).

QUANTITATIVE CORONARY ARTERIOGRAPHY

Coronary luminal diameter was measured by quantitative computerised analysis with an automated edge contour detection analysis system (Computerized Angiographic Analysis System, version 2V2; Pie Data Medical, Maastricht, The Netherlands) ${ }^{19}$ from end diastolic frames of each arteriogram. The stem of the coronary catheter was used for calibration to determine absolute measurement in millimetres, and correction was made for radiographic pincushion distortion.

VALIDATION OF THE QUANTITATIVE CORONARY ARTERIOGRAPHY

All the measured diameters were within $0.07 \mathrm{~mm}$ of the mean value of those obtained
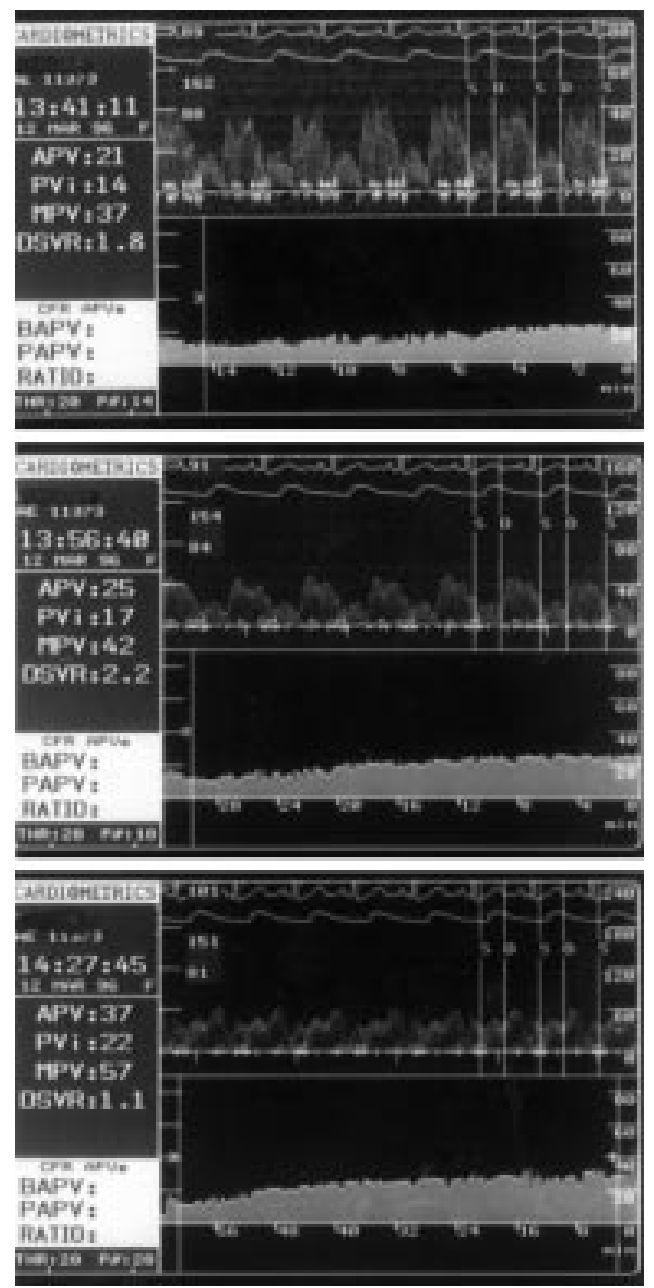

Figure 2 Coronary blood flow velocity in a patient with coronary artery disease 15 minutes (top) and 30 minutes (middle) after the initiation of $B Q-123$ infusion and after the end of the infusion (bottom). It can be seen that peak velocity integral (PVi) increases from 14 to 17 and $22 \mathrm{~cm}$, respectively, while systolic blood pressure decreases from 162 to 154 and $151 \mathrm{~mm} \mathrm{Hg}$. Note that the blood flow velocity scale is different in the three recordings.

from computerised measurement by two independent operators. Twenty four arterial segments were analysed by two independent observers and reanalysed at a later time. The mean intraobserver variation, expressed as the standard error of the estimate, was $0.10 \mathrm{~mm}$. The interobserver variation was $0.12 \mathrm{~mm}$.

All major coronary arteries were divided into thirds using the American Heart Association classification $^{20}$ and only angiographically good images were included in the study. Proximal and distal arterial segment changes (from baseline to the end of BQ-123 infusion) were studied. The proximal segment of the left anterior descending coronary artery was estimated over a short arterial segment immediately distal to the Doppler probe (approximately $5 \mathrm{~mm}$ from the Doppler guidewire).

The analysis of the angiograms was performed by two cardiologists who were unaware of the patients' clinical characteristics.

DOPPLER FLOW GUIDEWIRE

The flow velocity measurements were obtained using a Doppler flow guidewire (FloWire, Car- 
Table 2 Effects of normal saline on eight control subjects

\begin{tabular}{lll}
\hline & Baseline & Normal saline \\
\hline Heart rate (beats/min) & $70(4)$ & $69(5)$ \\
Mean blood pressure (mm Hg) & $110(4)$ & $112(5)$ \\
Proximal artery segment $(\mathrm{mm})$ & $3.04(0.29)$ & $3.00(0.30)$ \\
Distal artery segment $(\mathrm{mm})$ & $1.52(0.14)$ & $1.56(0.16)$ \\
PVi $(\mathrm{cm})$ & $16.5(4.0)$ & $14.3(3.1)$ \\
$\mathrm{CBF}(\mathrm{ml} / \mathrm{min})$ & $80(8)$ & $63(9)$ \\
$\mathrm{CVR}(\mathrm{mm} \mathrm{Hg} / \mathrm{ml} / \mathrm{min})$ & $2.17(0.60)$ & $2.40(0.68)$ \\
Plasma big ET-1 (fmol/ml) & $0.27(0.02)$ & $0.25(0.06)$ \\
\hline
\end{tabular}

Values are mean (SEM). There was no significant change between baseline and after normal saline administration.

$\mathrm{CBF}$, coronary blood flow of the left anterior descending artery; CVR, coronary vascular resistance of the left anterior descending artery; ET-1, endothelin-1; PVi, peak velocity integral.

diometrics, Mountain View, California, USA) which has been validated in vitro and in an animal model using simultaneous electromagnetic flow measurements for comparison. ${ }^{21}$

Coronary blood flow was calculated from the coronary blood flow velocity and the coronary artery diameter, ${ }^{22}$ using the formula: coronary blood flow $(\mathrm{CBF}, \mathrm{ml} / \mathrm{min})=\left(\pi \mathrm{D}^{2}\right) /$ $4 \times \mathrm{PVi} \times \mathrm{HR}$

where $\mathrm{D}$ is the diastolic diameter of the epicardial coronary artery in $\mathrm{cm}$, measured $5 \mathrm{~mm}$ beyond the tip of the Doppler guidewire, PVi is the peak velocity integral of the coronary blood flow velocity in $\mathrm{cm}$, and $\mathrm{HR}$ is the heart rate in beats/min.

The Doppler flow wire is a 0.014 inch $(0.36 \mathrm{~mm}), 175 \mathrm{~cm}$ long flexible and steerable guidewire having a floppy, shapable distal end with a $12 \mathrm{MHz}$ piezoelectric transducer mounted at the tip. The sample volume is positioned at a distance of $5.2 \mathrm{~mm}$ from the transducer and has an approximate width of $2.25 \mathrm{~mm}$ owing to the divergent ultrasound beam, so a large part of the flow velocity profile is also included in the sample volume for eccentric positions of the Doppler flow wire. After real time processing of the quadrature audio signal, a fast Fourier transform algorithm is used to increase the reliability of the analysis. The Doppler system calculates and displays several spectral variables on-line, including the averaged (mean of two beats) peak velocity, the peak velocity integral, and the maximum peak velocity, as shown in fig 2 . The peak velocity integral is the integral of the peak velocity of the whole cycle (diastole and systole).

Coronary vascular resistance was calculated from the mean arterial pressure (MAP, $\mathrm{mm} \mathrm{Hg}$ ), and coronary blood flow using the formula ${ }^{22}$ : coronary vascular resistance (CVR, $\mathrm{mm} \mathrm{Hg} / \mathrm{ml} / \mathrm{min})=\mathrm{MAP} / \mathrm{CBF}$

PLASMA BIG ET-1

Blood samples were drawn from the femoral vein at baseline and at the end of BQ-123 infusion for big ET-1 estimation. Plasma big ET-1, as a measure of ET-1 generation, ${ }^{23}$ was measured without need for extraction by an enzyme linked immunosorbent assay (Biomedica Gesellschaft, Vienna, Austria). Cross reactivity with big ET(1-38) is $100 \%$, and with big ET(22-38), ET-1, ET-2, and ET-3, < 1\%. Intra-assay variation was $4.9 \%$ and interassay variation, $6.9 \%$. Recovery from plasma spiked with big ET-1 was $96 \%$. The detection limit of the assay is $0.05 \mathrm{fmol} / \mathrm{ml}$ and the normal range is $<0.7 \mathrm{fmol} / \mathrm{ml}$.

\section{STATISTICAL ANALYSIS}

The values were analysed using the statistics program, version 5, of StatSoft Inc. All data are expressed as mean (SEM). In the study group, we used a $2 \times 2$ analysis of variance with one repeated measure, followed by post hoc comparison (Tukey's test) for the statistical analysis. In the control group we used analysis of variance with one repeated measure. Linear regression analysis using the least square difference and the analysis of variance was used in order to examine possible correlations between changes in coronary blood flow and resistance and baseline blood pressure and its changes, big ET-1, and smoking history. A probability value of $p<0.05$ was considered significant.

Table 3 The effects of BQ-123 on the studied variables in 14 individuals, mean (SEM) age 53 (2) years (nine men, five women)

\begin{tabular}{|c|c|c|c|c|}
\hline Variables & & Baseline & $B Q-123$ & $p$ Value \\
\hline \multirow[t]{3}{*}{ Heart rate (beats/min) } & All 14 subjects & $78(2)$ & $78(2)$ & NS \\
\hline & $\mathrm{CAD}(\mathrm{n}=7)$ & $76(3)$ & $76(4)$ & NS \\
\hline & Normal CA $(\mathrm{n}=7)$ & $79(3)$ & $78(3)$ & NS \\
\hline \multirow[t]{3}{*}{ Mean blood pressure $(\mathrm{mm} \mathrm{Hg})$} & All 14 subjects & $110(3)$ & $110(5)$ & NS \\
\hline & $\mathrm{CAD}(\mathrm{n}=7)$ & $109(5)$ & $102(5)$ & NS \\
\hline & Normal CA $(n=7)$ & $111(5)$ & $118(8)$ & NS \\
\hline \multirow[t]{3}{*}{ Proximal artery segment $(\mathrm{mm})$} & All 14 subjects & $2.90(0.12)$ & $3.06(0.13)$ & 0.03 \\
\hline & $\mathrm{CAD}(\mathrm{n}=7)$ & $2.92(0.18)$ & $3.19(0.23)$ & 0.01 \\
\hline & Normal CA $(n=7)$ & $2.88(0.18)$ & $2.94(0.14)$ & NS \\
\hline \multirow[t]{3}{*}{ Distal artery segment $(\mathrm{mm})$} & All 14 subjects & $1.50(0.08)$ & $1.67(0.07)$ & 0.0003 \\
\hline & $\mathrm{CAD}(\mathrm{n}=7)$ & $1.48(0.12)$ & $1.66(0.10)$ & 0.005 \\
\hline & Normal CA $(n=7)$ & $1.51(0.09)$ & $1.67(0.10)$ & 0.008 \\
\hline \multirow[t]{3}{*}{ PVi (cm) } & All 14 subjects & $13.7(1.0)$ & $16.0(1.3)$ & 0.06 \\
\hline & $\mathrm{CAD}(\mathrm{n}=7)$ & $13.7(1.3)$ & $15.6(1.4)$ & NS \\
\hline & Normal CA $(n=7)$ & $13.6(1.5)$ & $16.4(2.4)$ & NS \\
\hline \multirow[t]{3}{*}{$\mathrm{CBF}(\mathrm{ml} / \mathrm{min})$} & All 14 subjects & $75(10)$ & $92(10)$ & 0.006 \\
\hline & $\mathrm{CAD}(\mathrm{n}=7)$ & $73(12)$ & $94(13)$ & 0.02 \\
\hline & Normal CA $(n=7)$ & $77(17)$ & $89(15)$ & NS \\
\hline \multirow[t]{3}{*}{$\mathrm{CVR}(\mathrm{mm} \mathrm{Hg} / \mathrm{ml} / \mathrm{min})$} & All 14 subjects & $1.99(0.36)$ & $1.44(0.22)$ & 0.02 \\
\hline & $\mathrm{CAD}(\mathrm{n}=7)$ & $1.84(0.42)$ & $1.20(0.18)$ & NS \\
\hline & Normal CA $(n=7)$ & $2.14(0.62)$ & $1.68(0.41)$ & NS \\
\hline \multirow[t]{3}{*}{ Plasma big ET-1 (fmol/ml) } & All 14 studied subjects & $0.28(0.03)$ & $0.33(0.04)$ & NS \\
\hline & $\mathrm{CAD}(\mathrm{n}=7)$ & $0.28(0.03)$ & $0.28(0.02)$ & NS \\
\hline & Normal CA $(n=7)$ & $0.29(0.05)$ & $0.39(0.08)$ & NS \\
\hline
\end{tabular}

Seven subjects had normal coronary arteries (CA) and seven had coronary artery disease (CAD). Values are given as mean (SEM). For rest of abbreviations see table 2 . 

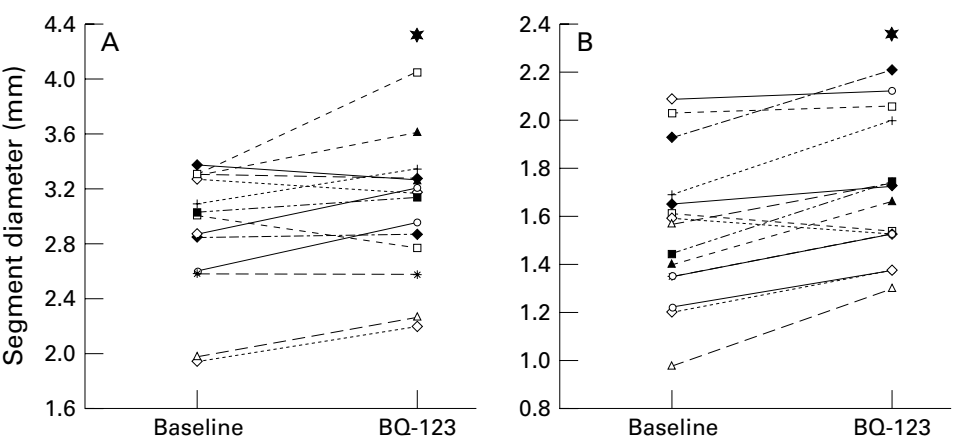

Figure 3 Line plots of the diameter of the $(A)$ proximal and $(B)$ distal arterial segments after BQ-123 administration. The vasodilatation of the distal segments was greater $(p<$ $0.05)$ than that of the proximal segments. ${ }^{\star} p<0.05 v$ baseline.
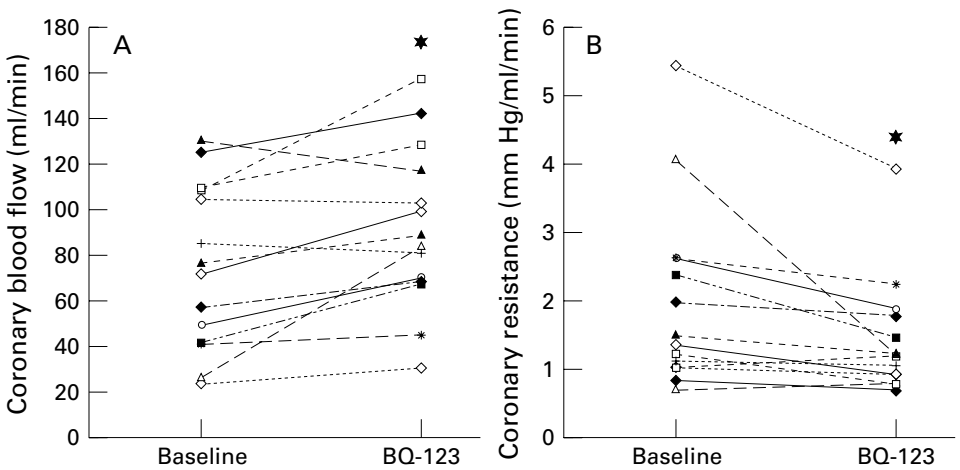

Figure 4 Line plots of $(A)$ coronary blood flow and $(B)$ vascular resistance after BQ-123 administration. ${ }^{\star} p<0.05 v$ baseline.

\section{Results}

No adverse effects from the study protocol were recorded.

CONTROL GROUP

The effects of normal saline in the control group are shown in table 2 . Heart rate, blood pressure, and artery diameter remained unchanged after normal saline infusion. Peak velocity integral, coronary blood flow, and resistance also remained unchanged after normal saline administration.

STUDY GROUP

In the study group, heart rate and blood pressure did not change after BQ-123 administration (table 3). Proximal artery segment dimension increased by 6 (2)\% after BQ-123 ( $\mathrm{p}<0.05 v$ baseline) (fig 3). Distal artery segment dimension increased by 12 (3) \% after BQ-123 ( $\mathrm{p}<0.05 v$ baseline) (fig 3). The increase in the distal arterial segment after BQ-123 was $11(3) \%$ and $14(5) \%(p>0.05)$ in patients with and without coronary artery disease, respectively (table 3 ). The vasodilator effect of BQ-123 was greater $(p<0.05)$ in the distal than in the proximal segments.

The peak velocity integral showed a trend to increase after BQ-123 (table 3). Coronary blood flow increased by 17 (5) $\mathrm{ml} / \mathrm{min}$ after BQ-123 administration ( $\mathrm{p}<0.05 v$ baseline) (table 3, fig 4). The increase of coronary blood flow after BQ-123 was similar $(p>0.05)$ in patients with and without coronary artery disease.

Coronary vascular resistance decreased by $0.55(0.21) \mathrm{mm} \mathrm{Hg} / \mathrm{ml} / \mathrm{min}(\mathrm{p}<0.05)$ after
BQ-123 administration, and the changes were similar in patients with and without coronary artery disease (table 3, fig 4). An analysis of variance and linear regression analysis did not show any relation between the BQ-123 responses and heart rate, blood pressure, or big ET-1 changes.

Plasma big ET-1 was similar in patients with and without coronary artery disease and in control subjects. It did not change significantly after BQ-123. There was no significant correlation between the baseline big ET-1 and the effect of a 60 minute infusion of BQ-123 on the coronary blood flow $(r=-0.02, \mathrm{p}>0.05)$ or on coronary vascular resistance $(r=-0.19$, $\mathrm{p}>0.05)$.

\section{Discussion}

Our study shows that inhibition of the actions of endogenous ET-1 at the $\mathrm{ET}_{\mathrm{A}}$ receptor causes coronary vasodilatation, mainly in the distal arterial segments, and increases coronary blood flow in patients undergoing coronary arteriography. Because responses were similar in subjects with and without coronary artery disease, this provides clear evidence for the first time of a physiological role for endogenously generated ET-1 in the regulation of coronary vascular tone, extending earlier observations in the peripheral vasculature. ${ }^{5}$

A greater percentage increase in coronary artery diameter was observed in the smaller than in the larger epicardial vessels after BQ-123 - an effect similar in magnitude, but of opposite nature, to the withdrawal of nitric oxide mediated dilator tone associated with intracoronary administration of the nitric oxide synthase inhibitor, L-N ${ }^{\mathrm{G}}$-monomethylarginine. ${ }^{24} \mathrm{~A}$ similar finding has been reported previously for glyceryl trinitrate, ${ }^{25}$ atrial natriuretic factor, ${ }^{26}$ and other coronary vasodilators. ${ }^{27}$ However, the mechanism of this differential response remains unclear. Previous investigators have suggested that this differential effect on small rather than large epicardial arteries reflects increased basal coronary tone or hypersensitivity of the distal coronary artery segments to coronary vasodilators. ${ }^{28}$ The hypersensitivity may be caused by an alteration in the neural receptor responses of the smooth muscle cell membrane properties, ${ }^{29} 30$ or by an inherent difference in the pharmacological behaviour of the smooth muscle at different levels of the coronary arterial tree. ${ }^{26}$

The results of this study are consistent with the effects of exogenously administered ET-1 on coronary vascular tone. ${ }^{13}$ Cannan and colleagues showed in anaesthetised dogs that ET-1 at pathophysiological concentrations mediates coronary vasoconstriction through the $\mathrm{ET}_{\mathrm{A}}$ and not the $\mathrm{ET}_{\mathrm{B}}$ receptor. ${ }^{12}$ Recently, it was also found that $\mathrm{ET}_{\mathrm{B}}$ receptors do not contribute to ET-1 induced vasoconstriction in isolated human coronary arteries. ${ }^{31}$ The $\mathrm{ET}_{\mathrm{A}}$ receptor is widely present in vascular smooth muscle and is highly expressed in coronary vessels. Stimulation of the $\mathrm{ET}_{\mathrm{A}}$ receptors by their natural ligand, ET-1, which is derived from the adjacent endothelium and in some cases from high concentrations in plasma, 


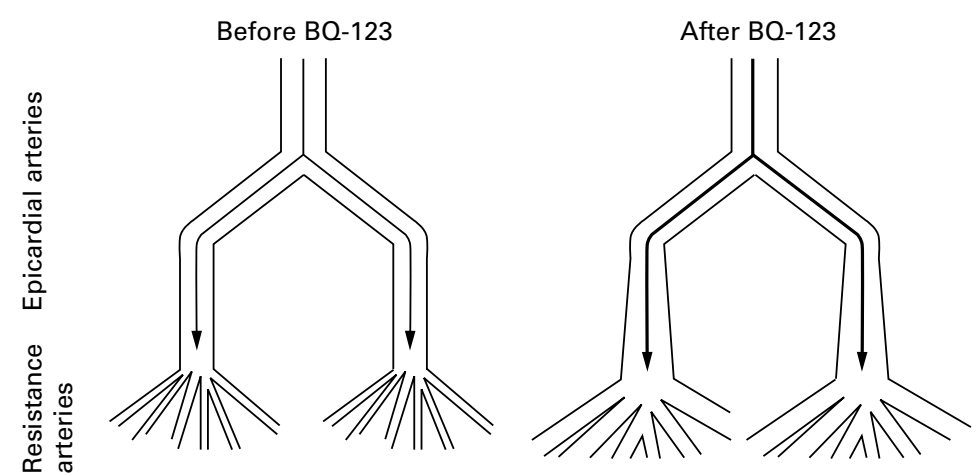

Figure 5 Schematic representation of the coronary arterial bed and possible effects of $E T_{A}$ antagonism. Coronary arteries can be divided into two functional components: large epicardial conductance arteries and smaller resistance arterioles. ET antagonism dilates the distal epicardial arterial segments and the resistance vessels more than the proximal arterial segments, causing a decrease in coronary artery resistance and an increase in blood flow.

causes $\mathrm{G}$ protein coupled activation of phospholipase $\mathrm{C}$ and an increase in intracellular calcium; this is linked to increases in intracellular inositol triphosphate and membrane diacyglycerol. ET-1 is now thought to be produced continuously within the endothelium of peripheral blood vessels and the coronary circulation, to provide a contribution to endogenous vascular tone. $\mathrm{ET}_{\mathrm{A}}$ antagonists are thought to produce vasodilatation by local withdrawal of this ET-1 mediated tone caused by tonic stimulation of the $\mathrm{ET}_{\mathrm{A}}$ receptors. In addition, when the $\mathrm{ET}_{\mathrm{A}}$ receptors are blocked by $\mathrm{ET}_{\mathrm{A}}$ antagonists, endogenous ET-1 may act predominantly on the endothelial $\mathrm{ET}_{\mathrm{B}}$ receptors to release nitric oxide, ${ }^{7}$ which makes an additional contribution to the reduction in vascular tone and the resultant vasodilatation. Although the $\mathrm{ET}_{\mathrm{A}}$ receptor appears to be the major receptor responsible for ET-1 mediated vasoconstriction, further studies with selective $\mathrm{ET}_{\mathrm{B}}$ receptor antagonists, such as BQ-788, ${ }^{7}$ are necessary to determine the physiological role of $\mathrm{ET}_{\mathrm{B}}$ receptors in the coronary circulation.

Coronary arteries can be divided into two functional components: large epicardial conductance arteries and smaller resistance arterioles. We found that distal epicardial arterial segments dilated more than the proximal epicardial segments. We also showed a decrease in coronary vascular resistance as a consequence of vasodilatation of the resistance arterioles (fig 5). $\mathrm{ET}_{\mathrm{A}}$ receptors may therefore be mainly concentrated in, or be more important in, the distal segments. Consequently, the resistance vessels of the human coronary vasculature are the major site of action after $\mathrm{ET}_{\mathrm{A}}$ receptor blockade with $\mathrm{BQ}-123$. This is in accordance with the findings of Rigel and Lappe, ${ }^{32}$ who showed that in anaesthetised dogs conduit and resistance coronary vasoconstriction were mediated by the $\mathrm{ET}_{\mathrm{A}}$ receptor, with the $\mathrm{ET}_{\mathrm{A}}$ receptor being potentially important in mediating resistance vessel constriction.

We used an $\mathrm{ET}_{\mathrm{A}}$ selective dose of $\mathrm{BQ}-123$ which is at - or more likely just below-the dose that causes changes in systemic haemodynamics. This is important. A recent study examined the effects of bosentan on systemic haemodynamics and epicardial coronary artery tone in patients with ischaemic heart disease, ${ }^{33}$ but because the drug was not given locally and most of its effect would have been on the systemic circulation, it is not clear from that paper whether the effect is a direct one or is mediated indirectly through neurohormonal mechanisms.

Although the dose of BQ-123 was chosen to achieve maximum inhibition at $\mathrm{ET}_{\mathrm{A}}$ receptors, based on the forearm infusion studies, ${ }^{5}$ we did not study higher doses, so we cannot say with certainty that we have seen the maximum possible local effects of $\mathrm{ET}_{\mathrm{A}}$ blockade. Against this, studies in hand veins show that the effects of exogenous ET-1 are modulated by dilator prostanoids. ${ }^{34}$ Hence, aspirin pretreatment of the patients may have enhanced the constrictor potential of endogenous ET- 1 if coronary vessels behave in a similar manner to the hand veins. Before the study, all our patients received heparin, which can interact with mediators of the vascular endothelium, possibly through a nitric oxide mediated mechanism. ${ }^{35}$ Administration of heparin was required by the experimental protocol, but as the same dosage was given to the control subjects we believe that our results were not affected.

Plasma big ET-1 concentrations are believed to provide a measure of global vascular ET-1 generation, albeit a poor one. ${ }^{23}$ We hypothesised, therefore, that plasma big ET-1 might predict the coronary vasodilator response to BQ-123. In the event, plasma big ET-1 did not appear to be valuable in this regard.

\section{CONCLUSIONS}

Our study shows that endogenously generated ET-1 contributes to the maintenance of coronary vascular tone in humans, acting at least in part through $\mathrm{ET}_{\mathrm{A}}$ receptors. Because these effects were present in subjects with coronary artery disease as well as in those without, endothelin receptor antagonists may thus have potential as vasodilator agents in the treatment of coronary artery disease.

We would like to thank the Elpen Pharmaceutical Company for the preparation of the BQ-123 for human use. DJW is supported by a research leave fellowship from the Wellcome Trust (WT 0526330).

1 Yanagisawa M, Kurihawa $\mathrm{H}$, Kimura S, et al. A novel potent vasoconstrictor peptide produced by vascular endothelial cells. Nature 1988;332:411-15.

2 Inoue A, Yanagisawa $M$, Kimura $S$, et al. The human endothelin family: three structurally and pharmacologically distinct isopeptides predicted by three separate genes. Proc Natl Acad Sci USA 1989;86:2863-7.

3 Haynes WG, Webb DJ. The endothelin family of peptides: local hormones with diverse roles in health and disease? Clin Sci 1993;84:485-500.

4 Webb DJ, Haynes WG. Endothelin come of age. Lancet

4 Webb DJ, Hayn-4 WG. Endothelin come of age. Lancet
$1993 ; 342: 1439-40$.
5 Haynes WG, Webb DJ. Contribution of endogenous generation of endothelin-1 to basal vascular tone. Lancet 1994;344:852-4.

6 Haynes WG, Ferro CJ, O'Kane KPJ, et al. Systemic endothelin receptor blockade decreases peripheral vascular resistance and blood pressure in humans. Circulation 1996; 93:1860-70.

7 Verhaar MC, Strachan FE, Newby DE, et al. Endothelin-A receptor antagonist-mediated vasodilatation is attenuated by inhibition of nitric oxide synthesis and by endothelin-B receptor blockade. Circulation 1998;97:752-6.

8 Webb DJ, Monge JC, Rabelink TJ, et al. Endothelin: new discoveries and rapid progress in the clinic. Trends Physiol Sci 1998;19:5-8.

9 Hamsen A, Franco-Cereceda A, Matran R, et al. Occurrence, specific binding sites and functional effects of
endothelin in human cardiopulmonary tissue. Eur $\mathcal{F}$ endothelin in human card 
10 Grover GJ, Sleph PG, Fox M, et al. Role of endothelin-1 and big endothelin-1 in modulating coronary vascular tone, Contractile function and severity of ische

11 Grover GJ, Dzwonczyk S, Parham CS. The endothelin-1 receptor antagonist BQ-123 reduces infarct size in a canine model of coronary occlusion and reperfusion. Cardiovasc Res 1993;27:1613-18.

12 Cannan CR, Burnett JC, Brandt RR, et al. Endothelin at pathophysiological concentrations mediates coronary vasoconstriction via the endothelin-A receptor. Circulation 1995;92:3312-17.

13 Pernow J, Kaijser L, Lundberg JM, et al. Comparable potent coronary constrictor effects of endothelin-1 and big endothelin-1 in humans. Circulation 1996;94:2077-82.

14 Bassan M, Ganz W, Marcus HS, et al. The effect of intracoronary injection of contrast medium upon coronary blood flow. Circulation 1975;51:442-5.

15 Wsineski JA, Gertz EW, Neeze R, et al. Myocardial metabolic alterations after contrast angiography. Am $\mathcal{f}$ Car diol 1982;50:239-45.

16 Ferro CJ, Haynes WG, Hand MF, et al. The vascular endothelin and nitric oxide systems in essential hyperendothelin and nitric oxide systems in es

17 de Berrazueta JR, Bhagat K, Vallance P, et al. Dose- and time-dependency of the dilator effects of the endothelin antagonist, BQ-123, in the human forearm. Br f Clin Phar macol 1997;44:569-71.

18 Ihara M, Noguchi K, Saeki T, et al. Biological profiles of highly potent novel endothelin antagonists selective for the ETA receptor. Life Sci 1992;50:247-55.

19 Reiber JHC, Serruys PW, Koouman C, et al. Assessment of short-, medium- and long-term variations in arterial dimensions from computer-assisted quantitation of coronary cineangiograms. Circulation 1985;71:280-8.

20 Austen WG, Edwards JE, Frye RL, et al. Reporting system on patients evaluated for coronary artery disease. Report of the ad hoc committee for grading of coronary artery disease, Council on Cardiovascular Surgery, American disease, Council on Cardiovascular Surgery,

21 Doucette JW, Corl DP, Payne HP, et al. Validation of a Doppler guidewire for intravascular measurement of coronary artery flow velocity. Circulation 1992;85:1899-911.

22 Takeuchi M Noty. Circulation reserve assessed by blood flow velocity analysis reflect absolute coronary flow reserve? Cathet Cardiovasc Diagn 1996;38:251-4

23 Plumpton C, Ferro CJ, Haynes WG, et al. The increase in human plasma immunoreactive endothelin but not big endothelin-1 or its C-terminal fragment indices by systemic administration of the endothelin antagonist TAK044. Br F Pharmacol 1996;119:311-14.

24 Lefroy DC, Crake T, Uren NG, et al. Effect of inhibition of nitric oxide synthesis on epicardial coronary artery caliber and coronary blood flow in humans. Circulation 1993;88: 43-54.

25 Feldman R, Pepine C, Conti R. Magnitude of dilatation of large and small coronary arteries by nitroglycerin. Circulation 1981;64:324-33.

26 Hermann HC, Rosenthal AD, Davis CA. Cardiovascular effects of intracoronary atrial natriuretic peptide administration in man. Am Heart f 1990;120:308-15.

27 Chew CYC, Brown BG, Singh BN, et al. Effects of verapamil on coronary hemodynamic function and vasomotility relative to its mechanism of antianginal action. $\mathrm{Am}$ 7 Cardiol 1983;51:699-705.

28 Simonetti I, Caterina R, Michelassi C, et al. Coronary vasodilation by nitrates is not mediated by prostaglandin system: a quantitative cineangiographic study. $\mathcal{F} \mathrm{Am}$ Coll Cardiol 1986;8:1263-70.

29 Zuberbuhler RC, Bohr DF. Responses of coronary smooth muscle to catecholamines. Circ Res 1965;16:431-40.

30 Schnaar RL, Sparks HV. Response of large and small coronary arteries to nitroglycerin, $\mathrm{NaNO}$ and adenosine. $A m$ f Physiol 1972;223:223-8.

31 Bax WA, VandenBrink AM, Saxena PR. Endothelin-B receptors do not contribute to ET-1 induced vasoconstriction in human isolated coronary arteries [abstract]. Fifth International Conference on Endothelin, Kyoto, Japan, 1997.

32 Rigel DF, Lappe RW. Differential responsiveness of conduit and resistance coronary arteries to endothelin $\mathrm{A}$ and $\mathrm{B}$ receptor stimulation in anesthetized dogs. $f$ Cardiovasc Pharmacol 1993;22(suppl 8):S243-7.

33 Wenzel RR, Fleisch M, Shaw S, et al. Hemodynamic and coronary effects of the endothelin antagonist bosentan in patients with coronary artery disease. Circulation 1998;98: 2235-40.

34 Haynes WG, Webb DJ. Endothelium-dependent modulation of responses to endothelin-1 in human hand veins. Clin Sci 1993;84:427-33.

35 Yokokawa K, Tahara H, Kohno M, et al. Heparin regulates endothelin production through endothelium-derived nitric oxide in human endothelial cells. F Clin Invest 1993;92: $2080-5$ 